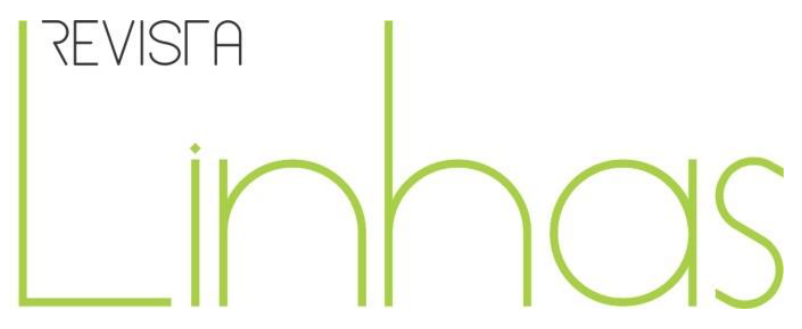

\title{
Os rastros das táticas - análise da movimentação funcional de um professor catarinense (décadas de 1910 - 1920) ${ }^{1}$
}

\begin{abstract}
Resumo
O presente artigo tematiza as manobras protagonizadas pelo professor primário Alberto Voigt na tentativa de reabrir sua escola, fechada em meio a iniciativas de nacionalização do ensino catarinense. Para tanto, foi organizada série documental composta por relatórios de governo, periódicos e ofícios expedidos pela Diretoria Geral de Instrução Pública, então dirigida por Henrique da Silva Fontes. Interessou inventariar as práticas do docente, entendendo-as como táticas lançadas em meio a um quadro de crescente burocratização da instrução e da docência. São então utilizadas as categorias de estratégias e táticas tais quais propostas por Michel de Certeau (2009). A análise do caso do professor Voigt faz também pensar o recrudescimento de mecanismos de seleção e recrutamento de professores em meio a um quadro de progressiva nacionalização da instrução catarinense (CAMPOS, 2008; 2006; FIORI, 1975; MOREIRA, 1954). Este artigo, por fim, estabelece uma relação entre esse processo nacionalizador a um maior controle e funcionarização (NÓVOA, 1997) da docência, ligando esses movimentos ao crescente aparelhamento de quadros de gerenciamento burocrático da instrução.

Palavras-chave: Educação e Estado - Santa Catarina - História. Burocracia. Professores. Educação - História.
\end{abstract}

\author{
Carolina Cechella Philippi \\ Universidade Estadual de Campinas \\ - UNICAMP - Campinas/SP - Brasil \\ carolinacechella@gmail.com
}

\footnotetext{
Para citar este artigo:

PHILIPPI, Carolina Cechella. Os rastros das táticas - análise da movimentação funcional de um professor catarinense (décadas de 1910 - 1920). Revista Linhas. Florianópolis, v. 21, n. 46, p. 333-351, maio/ago. 2020.
}

DOI: $10.5965 / 1984723821462020333$

http://dx.doi.org/10.5965/1984723821462020333

\footnotetext{
1 Artigo vinculado à pesquisa de doutorado em andamento, financiada pelo Conselho Nacional de Desenvolvimento Científico e Tecnológico (CNPq).
} 


\title{
Tactical tracking - analysis of the career movements of a teacher from Santa Catarina (1910-1920 decades)
}

\begin{abstract}
The present article thematizes maneuvers in which primary teacher Alberto Voigt found himself in his atempt to reopen his school, closed amidst nationalization initiatives in the State of Santa Catarina, Brazil. For this purpose, a documental series was organized, consisting of government reports, periodicals and office letters issued by the General Board of Public Instruction, then directed by Henrique da Silva Fontes. The teacher's practices were inventoried and seen as tactics employed in a scenario of crescent bureaucratization of both instruction and the teaching profession. The categories of strategies and tactics as proposed by Michel de Certeau (2009) apply. The analysis of teacher Voigt's case showcases an upsurge in mechanisms of selection and recruiting of educators in the context of progressive nationalization of education in Santa Catarina (Campos, 2008; 2006; Fiori, 1975; Moreira, 1954). Finally, this article relates the nationalizing process to a bigger control and the professionalization (Nóvoa, 1997) of educators, linking these movements to the increasing oversight of the bureaucratic management of instruction.
\end{abstract}

Keywords: State and education. Santa Catarina History. Bureaucracy. Teachers. Education. History. 


\section{Aspectos introdutórios}

Joinville (Santa Catarina), 22 de novembro de 1919. É no periódico bissemanal, O Município de Joinville, que são expostos aspectos considerados relevantes da trajetória funcional do professor Alberto Voigt ${ }^{2}$. É também nele que é retomada sua portaria de nomeação, exarada pelo Superintendente Municipal em exercício, Arthur Ferreira da Luz. Seu atestado de capacidade e bons serviços é acessado - em idioma alemão - no verso da portaria principal. O mesmo é traduzido e citado ainda neste editorial, sendo em seguida comentado:

[...] Note-se que Alberto Voigt, a quem foi dado o título de professor provisório, não era professor municipal [...] e sim professor particular, professor de escola estrangeira, professor de escola que já funcionava desde $1^{\circ}$ de janeiro de 1917, professor de escola fechada em novembro desse ano. Note-se tudo isso e veja se a nomeação que citamos [...] não houve uma "camouflage" 3 no sentido de burlar as ordens do Governo Federal e as disposições do decreto estadual 1063 [...], que reserva ao Secretário Geral a faculdade de conceder reabertura às escolas particulares fechadas por não ensinarem eficientemente a língua portuguesa. (SEM..., 1919, p. 2)

O título de nomeação teria sido uma forma de burlar as leis e normas legais, permitindo assim que um professor estrangeiro e não fluente em português permanecesse lecionando. Porém, não somente sua escola foi fechada como os trâmites para sua reabertura foram acompanhados mais de perto. A matéria prossegue, aproximando-se do final da história:

[...] Tendo o professor [...] requerido a reabertura da escola de Araponga, o senhor Secretário do Interior e Justiça mandou examiná-lo na forma do decreto 1063, pelo inspetor Orestes Guimarães, que organizou banca com professores [...] para ver se o requerente estava nas condições de bem poder cumprir a lei 1187, que exige que o professor

\footnotetext{
${ }^{2}$ O professor Alberto Voigt lecionou de janeiro de 1917 e maio de 1919 na escola de Rio da Luz, da qual foi demitido a pedido. Pouco depois, o docente solicitou a reabertura da escola de Araponga, no município de Blumenau. Foi então, nesse momento, requisitada a prestação de exame comprovando sua aptidão para tanto (A REPÚBLICA, 4 de novembro de 1919, p. 1). Maiores informações sobre sua movimentação funcional não foram rastreadas nos jornais indexados na hemeroteca da Biblioteca Nacional, e nem tampouco nos ofícios analisados na tese de doutoramento à qual esse artigo se articula.
}

3 Optou-se por preservar a grafia original dos documentos transcritos no corpo deste artigo. 
particular lecione em português as seguintes matérias: leitura, geografia e história pátria, educação física e cantos. (SEM..., 1919, p. 2)

O resultado do exame do docente é, então, veementemente destacado:

Pois bem, esse professor [...] foi unanimemente reprovado [grifo do autor] pela banca porque ele absolutamente não fala a língua vernácula e desconhece as matérias que, por lei estadual, é obrigado a ensinar. As provas escritas do Sr. Voigt estão na Diretoria de Instrução, e esse senhor está vivo e são e pode ser procurado por quem duvidar do que afirmamos, isto é, que [...] não fala a língua portuguesa. (SEM..., 1919, p. 2, grifo nosso)

Os excertos acima fazem ver os rastros das táticas mobilizadas pelo supracitado professor, entendendo-as como parte de uma movimentação funcional no interior dos quadros de gerenciamento burocrático do magistério e da instrução. O objeto deste artigo são as práticas nas quais essas táticas se alicerçaram. Interessou rastrear as operações lançadas na tentativa de reabertura de sua escola primária, bem como as formas pelas quais elas se relacionaram a uma hierarquia burocrática e funcional já estabelecida junto à Diretoria Geral da Instrução Pública. Para tanto, lança-se mão das definições de táticas e estratégias tais quais apresentadas por Michel de Certeau (2009) e toma-se emprestado o entendimento que Formosinho (2007) dá à burocracia. Esse objeto é circunscrito através da organização de série documental composta por jornais e periódicos da época, bem como a legislação educacional e a comunicação oficial expedida na ocasião. Os primeiros foram acessados através da Hemeroteca Digital da Biblioteca Nacional ${ }^{4}$, e os segundos através de visita ao Arquivo Público do Estado de Santa Catarina 5 .

Uma nova matéria sobre o fechamento das escolas primárias não enquadradas nos parâmetros de nacionalização do ensino foi apresentada, pouco tempo depois, no

\footnotetext{
${ }^{4}$ Biblioteca Nacional Digital Brasil. Disponível em: <http://memoria.bn.br/hdb/periodico.aspx>. Acesso em: 07 jan. 2019.

5 Conferir: Secretaria de Estado de Administração. Disponível em: <http://www.sea.sc.gov.br/index.php/institucional/diretorias/dioesc/arquivo-publico/sobre-a-instituicao >. Acesso 07 jan. 2019.
} 
jornal A República. É sob o título Pela nacionalização do ensino que o mesmo dispõe a seguinte reportagem:

[...] Sobre o decreto 1290, mandando sustar o funcionamento das escolas particulares e municipais de Joinville, por exorbitarem as determinações contidas em leis federais e estaduais em vigor, estranhamos que o governo ignora haver essa municipalidade dado fiel cumprimento a todas as disposições regulamentares sobre instrução, quando foi das complicações internacionais que motivaram uma quase completa reforma do ensino primário nesse município. (O DECRETO..., 1919, p. 1, grifo nosso)

São, em seguida, listadas as remodelações encampadas pelas autoridades municipais nessa ocasião, segundo o jornal: fechamento de quarenta e sete escolas estrangeiras e abertura de outras tantas, agora de acordo com os regulamentos promulgados, bem como o exame dos professores regentes (O DECRETO..., 1919, p. 1). Tais exigências já haviam sido listadas no decreto estadual de número 1063, de 8 de novembro de 1917, que versava a respeito dos conteúdos ministrados. Segundo ele:

Art. 1. As escolas estrangeiras deverão incluir nos seus programas o ensino das seguintes matérias, em língua vernácula:

1) linguagem oral e escripta;

2) historia do Brasil e educação cívica;

3) geographia do Brasil;

4) cantos e hymnos patrióticos. (SANTA CATARINA, 1919, p. 8)

O supracitado decreto serviu de mote para o fechamento de um número significativo de escolas estrangeiras concentradas principalmente em regiões de colonização teuta. O decreto 1290, de outubro de 1919, vem para arbitrar sua abertura e fechamento ainda de acordo com essas prerrogativas:

Ficam desde já fechadas as escolas particulares reabertas em Blumenau e Joinville e em outros quaisquer municípios do Estado com transgressão do decreto n. 1063, de 8 de novembro de 1917, e bem assim as escolas particulares ou municipaes regidas por professores que, impedidos de funcionar em virtude das ordens do Governo Federal baixadas em 1917, não tenham sido examinados de acordo com a legislação estadual. (SANTA CATARINA, 1919, p. 12, grifo nosso) 
Em que pesem as contradições, é por meio das rusgas a respeito do fechamento da escola específica na qual Alberto Voigt atuava e de sua aptidão ou não para continuar lecionando, que é deflagrado um cenário de progressiva demanda sobre a nacionalização da instrução pública catarinense. Embora destoantes em alguns aspectos, ambos os excertos de jornais supracitados sublinham a maior atuação do poder público e a progressiva promulgação de leis que tornam exigência legal para exercício da profissão docente o ensino da língua portuguesa, bem como da história e geografia brasileiras. Ao não cumprimento dessas deliberações é condicionado o funcionamento da unidade escolar. Em outras palavras: a instituição cujo professor não cumprir tais determinações teria suas atividades sumariamente encerradas, ficando sua abertura condicionada à prestação de exames do professor, provando assim sua proficiência em assuntos que versam sobre a nacionalidade brasileira.

Todavia, apesar desse contexto de firme cerceamento de sua atuação e de sua anunciada reprovação nos exames chefiados pelo Inspetor Federal Orestes Guimarães, Alberto Voigt lançou mão de outras manobras na tentativa de ver sua escola reaberta. É em torno dessa rusga, e da movimentação que a partir dela se engendrou, que este artigo se organiza. Inicialmente, apresenta o caso que envolveu o professor Alberto Voigt, situando-o nos quadros de gerenciamento burocrático da instrução. Nesse movimento, considera os rastros do docente enquadrando-os em uma estrutura burocrática politizada. Interessou também relacionar o caso pontual a um momento de mudança na representação vigente a respeito da instituição escolar. Em seguida, considera sua movimentação funcional no interior de um quadro de funcionarização6 (NÓVOA, 1997, p. 13-33) do professorado local. Por fim, são elencadas considerações sobre seus efeitos no professorado catarinense e sua articulação a uma crescente nacionalização da docência.

\footnotetext{
${ }^{6}$ Por funcionarização se entende a articulação da movimentação funcional a políticas de controle e coerção mais explícitas. No entendimento proposto neste artigo, defende-se que ela tem o efeito de articular a carreira do magistério a formas específicas de ingresso, permanência, exercício e exoneração. Conferir: NÓVOA, 1997.
} 


\section{O gerenciamento burocrático da instrução}

Alberto Voigt, porém, tentou ainda recorrer das decisões, advogando pela reabertura da escola. Suas manobras foram noticiadas ao Inspetor das Escolas Subvencionadas pela União, Orestes Guimarães 7 , e reportados pelo delegado regional, Freitas Meira, no seguinte telegrama:

[...] vindo a Blumenau conversar convosco a respeito do fechamento de sua escola, encontrou o deputado Luiz Abry, que o mandou voltar pra casa descansado e reabrir sua escola. A comunidade, porém, não consentiu que fosse reaberta a escola de Voigt [...]. (A NACIONALIZAÇÃO, 1920, p. 8, grifo do autor)

A respeito disso, manifestou-se o Secretário do Interior e Justiça, José Boiteux, em telegrama direcionado ao deputado:

Ciente da vossa indevida intervenção sobre as escolas mandadas legalmente fechar pelo Inspetor Federal, o governador encarregou-me de dizer-vos que lamenta que não estejas concorrendo a uma solução satisfatória à nacionalização do ensino. 0 governo está decidido a manter as mesmas atitudes que o governo federal, que muito acertadamente aprova o ato dessa autoridade. (A NACIONALIZAÇÃO, 1920 , p. 8, grifo do autor)

Prevaleceu, portanto, o despacho do Inspetor Orestes Guimarães. Ele foi encampado pelo Governador do Estado e também pelo então diretor da Diretoria Geral da Instrução Pública, Henrique Fontes ${ }^{8}$. Esse, empossado do cargo desde maio de 1919, expediu ofícios recorrentes tematizando o fechamento de unidades escolares em desacordo com as rotinas de nacionalização do ensino.

\footnotetext{
7 Professor paulista responsável pela remodelação do Colégio Municipal de Joinville (1906). Em 1910, foi contratado, sob comissão, pelo governador Vidal Ramos para reformar o ensino no estado de Santa Catarina (MOREIRA, 1954; FIORI, 1975). A Reforma Orestes Guimarães inicia-se no ano de 1911, sendo tema recorrente de estudo na História da Educação em Santa Catarina (conferir: TEIVE, Gladys Mary Ghizoni. Uma vez normalista, sempre normalista: cultura escolar e produção de um habitus pedagógico (Escola Normal Catarinense -1911-1935). Florianópolis: Insular: 2008).

8 Educador catarinense nascido em 1885 e falecido em 1966. Lecionou no Gymnasio Catharinense em 1910 e atuou como chefe escolar na capital antes de assumir o cargo de Diretor da Instrução Pública (PIAZZA, 1985; PROCHNOW, 2009).
} 
As medidas tomadas em prol da nacionalização do ensino no estado foram também tematizadas em outros espaços. Elas são tema nas páginas do jornal O Município de Joinville, que se posiciona em editorial nomeado Sem commentarios e as liga à pungente atuação do governador Hercílio Luz9:

Os seus atos resolutos [do governador] são prova de uma visão segura, de extraordinária apreensão dos assuntos mais complexos, e não sinal de que a Vossa Excelência se deixe sugestionar por ideias alheias, por terrores ou invencionices de informantes desequilibrados ou malévolos. (SEM..., 1919, p. 2)

As mesmas medidas são parte fulcral do relatório de governo que o próprio Hercílio Luz apresentou à Assembleia Legislativa de Santa Catarina no início do ano seguinte. Segundo ele:

O elemento estrangeiro, justiça se lhe faça, tem recebido com respeito as medidas administrativas e enviado todos os esforços para dar fiel cumprimento às disposições que regem os estabelecimentos particulares de ensino. Uma fiscalização constante e enérgica, sem violências, ao lado de uma propaganda bem encaminhada das vantagens práticas do conhecimento da língua, história e geografia do Brasil, muito tem contribuído para fazer desaparecer as prevenções dos que pareciam inadaptáveis aos nossos costumes. (SANTA CATARINA, 1920, p. 5)

O governador diz ainda que os atos de desrespeito à legislação promulgada foram facilmente contornados:

O simples ato do governo do estado, mandando fechar aquelas escolas municipais, que funcionavam com flagrante desobediência das disposições legais, foi o bastante para que a situação se normalizasse e os dirigentes daquele município providenciassem logo no sentido de serem cumpridas as formalidades exigidas. (SANTA CATARINA, 1920, p. 5)

A eficiente fiscalização do ensino, tematizada no mesmo relatório de governo, é citada como ponto vital de sua atuação. Ao exercício fiscalizador articularam-se as deliberações também encampadas pela Diretoria Geral da Instrução Pública local, que

\footnotetext{
9 Político catarinense nascido em 1860, com ano de falecimento em 1924. Ocupou cargo de governador do estado entre 1894 e 1898, 1918 e1922, e entre 1922 e1924 (PIAZZA, 1985).
} 
tinha como diretor Henrique Fontes. O mesmo exercício foi tematizado na série de ofícios expedidos e recebidos pelo órgão e assinados pelo seu dirigente. Esses, acondicionados no Arquivo Público do Estado de Santa Catarina, compuseram série documental mobilizada neste artigo, juntamente com os jornais e periódicos veiculados no período.

Henrique da Silva Fontes ocupou o cargo de diretor do ensino catarinense até 1926. Na vigência de sua direção ocorreram alterações nas propostas acerca da instrução primária e na adoção de obras didáticas. É nesse mandato que é adotada a Série de Leitura Fontes ${ }^{10}$ nas instituições de ensino no estado, substituindo o uso da Série de Leitura Viana, anteriormente indicada por Orestes Guimarães. Entende-se que, ao publicar série de leitura graduada visando à escola primária de Santa Catarina, o dirigente do ensino no estado liga a alfabetização a um saber organizado e seriado. Também nesse movimento fica facilitada a fiscalização em torno do que é ensinado nas escolas primárias, sendo ele justificado pelo foco crescente na fiscalização da instrução conforme percebido na leitura da série de ofícios. Vale, porém, perceber as movimentações de Henrique Fontes e Orestes Guimarães: em que pesem as rusgas a respeito da série de uso didática a ser adotada na instrução primária local, o veredicto do inspetor federal Orestes Guimarães sobre a reprovação do professor Voigt não foi questionado pelo diretor da instrução.

Henrique Fontes teve uma trajetória funcional que não foi incomum entre seus colegas. Antes da chefia da Diretoria da Instrução, o mesmo ocupou cargos de professor da Escola Normal Catarinense e de inspetor escolar. Foi por esse meio que galgou espaço na movimentação dos sujeitos políticos. Construiu, portanto, lugar de legitimidade para si e para a publicação pedagógica que posteriormente encabeçou, sendo que a mesma substituiu aquela indicada por Orestes Guimarães. Foi também sua trajetória pregressa que galgou sua ascensão na carreira burocrática do magistério e sua articulação com demais dirigentes do estado. Da forma como aqui se entende, a construção dos quadros de gerenciamento da instrução pública respondeu também a critérios políticos de recrutamento. Foram esses critérios que regeram a movimentação funcional e a tramitação dos despachos de determinados sujeitos.

\footnotetext{
${ }^{10}$ Segundo Prochnow (2009, p. 75-76), A Série Graduada de Leitura Fontes era composta por uma cartilha e mais quatro livros de leitura. A edição da primeira e dos dois primeiros livros seriados se deu em 1920, do terceiro em 1929 e do quarto em 1930.
} 
A atuação mais enfática dos inspetores escolares no controle burocrático e nas vistorias periódicas das unidades escolares - tal qual assinalada na leitura da série de ofícios aqui mobilizada ${ }^{11}$ - conversa com o recrudescimento das preocupações declaradas com a nacionalização do ensino na gestão de Henrique Fontes. Entre 1919 e 1920, foi comum a solicitação para reabertura de escolas anteriormente fechadas por esse motivo. O pedido, encaminhado ao inspetor, era noticiado por Henrique Fontes ao então Secretário do Interior e Justiça, José Boiteux. Mais de uma vez, porém, houve o indeferimento, apesar de todos os trâmites. Em mais de uma situação, Henrique Fontes reporta a reabertura de escola irregular e à revelia das ponderações dos Inspetores. Nesses casos, solicitou, como em ofício expedido em 20 de fevereiro de 1920, a intervenção de forças policiais (DIRETORIA GERAL DA INSTRUÇÃO PÚBLICA, 1920, Of., 392, Fl. 20).

Ao longo de toda a série de comunicações enviadas em 1921, foi constante o tema do funcionamento ilegal dessas instituições. Nesses casos, pede que o Secretário do Interior e Justiça, destinatário dessa expedição, envie Chefe de Polícia para providenciar sua interdição e fechamento. Tamanhos esforços para enquadramento institucional a fim de promover a instrução e nacionalização fazem pensar acerca das funções sociais das quais a escola era então incumbida. A centralidade em uma formação que torne o docente apto a uma atuação e intervenção em áreas de imigração alemã, já anunciada nos programas da Escola Normal Catarinense, corrobora o entendimento da escola como fator de incorporação e nacionalização. Para tanto, interessava expandir sua atuação e aparelhar sua estrutura.

O professor que dela se encarregava era, pois, central. Esse entendimento ratifica o rastreado por Marta Carvalho (2003a, p. 225-251; 2003b, p. 143-164) no mesmo período, porém no estado de São Paulo. Essa convergência assinala para o trânsito e aplicação de um modelo extensivo de expansão da escola e alfabetização, segundo o qual a instrução era vista como forma de incorporação do estrangeiro à nação. Esse modelo, porém, foi

\footnotetext{
11 Já em 1919, no primeiro ano de sua gestão, Henrique Fontes envia 19 ofícios a inspetores de diferentes circunscrições do estado. Neles, encaminhou também ao Secretário do Interior e Justiça solicitações constantes de verbas para exercícios da inspetoria. Em 1920 e 1921 centra suas expedições em envios ao Secretário do Interior e Justiça e, em 1925, ao Diretor do Tesouro. Apenas em 1926, o envio à inspetoria é retomado em série de 123 expedições.
} 
tensionado e matizado pelos diferentes sujeitos políticos ao longo de sua difusão. Cabe, a respeito disso, destacar que em Santa Catarina a rotina do fechamento de escolas e a tematização acerca dos critérios de recrutamento e permanência na carreira docente continuaram a ser veementemente tematizados na série de ofícios acessada, o que assinala para sua perenidade.

A nacionalização do ensino foi também tratada na historiografia da educação catarinense por diferentes vieses. Moreira (1954) e Fiori (1975) articulam os esforços legais de promoção da nacionalização a iniciativas de remodelação do ensino no estado. Cynthia Machado Campos também vai nessa direção ao tratar das intervenções em escolas locais, sobretudo na década de 1930, período de vigência da interventoria de Nereu Ramos (CAMPOS, 2008). Ainda sobre as intervenções feitas para a normalização das condutas da população catarinense e a paulatina nacionalização do ensino no estado, aproxima-se das iniciativas de promoção do idioma português em "A política da língua na Era Vargas". Ao abordar, nesse movimento, a repressão sofrida por imigrantes teutos a respeito do idioma falado, tematiza também suas resistências e respostas (CAMPOS, 2006).

O presente artigo considera e se insere nessas tematizações, mas centrando-se no aparelhamento burocrático dessa coerção e na criação de mecanismos de recrutamento sistematizados do professorado. Entende-se que a criação de mecanismos de coerção opera pelo aparelhamento de quadros de gerenciamento burocrático capazes de circunscrever e tratar das ocorrências de descumprimento e resistência à legislação. Uma dessas ocorrências tematizou o funcionamento da instituição escolar chefiada por Alberto Voigt, bem como as táticas mobilizadas na tentativa de sua reabertura. $O$ termo é retomado segundo os postulados de Michel de Certeau (2009), que o toma como uma categoria para entendimento das práticas cotidianas. A mesma categoria é nuançada, já em sua obra, como parte de um jogo polemológico, no qual confrontos e deslocamentos constantes se fazem ver. Ainda segundo Certeau (1985, p. 8), a polemologia diz respeito à consideração das práticas cotidianas como defesas para a vida. Sendo assim, elas se inserem como intervenções em uma relação de forças, caracterizada como um conflito permanente. Nesse jogo, há uma dinâmica clara: quanto mais desfavorecido, mais 
necessária é a malícia e a astúcia. É a essas práticas - que o autor categoriza como táticas - que se articulam as defesas para a vida e para a sobrevivência.

A categorização das práticas ordinárias apresentada por Michel de Certeau deu tônus para o entendimento das manobras do professor Alberto Voigt na tentativa de reabertura de sua escola. Porém, coadunando com o entendimento do autor, também aqui essas operações são nuançadas: as táticas do docente são alinhavadas em meio a um quadro de gerenciamento burocrático da instrução. É nesse meio hostil que o mesmo busca respaldo para sua atuação. Em outros termos: as táticas são esboçadas no interior de um meio pouco receptivo. São, ainda retomando Certeau, as "artes do fraco".

Em contraposição à categoria de táticas, mas ainda no interior do jogo polemológico, é apresentada a categoria “estratégias". A ela correspondem as operações lançadas a partir de um lugar próprio. São, pois, as práticas de gestão, gerenciamento e organização do outro que são operadas a partir de um lugar institucionalizado. No esforço interpretativo encampado neste artigo, às estratégias correspondem às ações operadas a partir dos órgãos de gerenciamento da instrução. Cabe, porém, entender o jogo constante entre estratégias e táticas, matizando-o. Mais que enquadrar as práticas do docente como táticas e os órgãos oficiais de gerenciamento do ensino como locais estratégicos de gestão, cabe entender as operações lançadas por ambos como parte de um jogo polemológico. Cabe também, além disso, operar com as categorias para entender as manobras do professor como uma tentativa de permanência no interior da maquinaria burocrática da instrução.

A articulação burocrática no gerenciamento da instrução foi tema de estudo de Formosinho (2007). Aproximando-se da instituição escolar, ele avança na análise da constituição da pedagogia burocrática ${ }^{12}$ (FORMOSINHO, 2007, p. 293-328). Da forma como entende a ação burocrática de administração da educação, passa a imperar um modelo de decisão no qual um autor anônimo é veiculado. O autor anônimo então

\footnotetext{
${ }^{12}$ Em texto no qual retoma reformas de ensino propostas em Portugal nos anos 80 e 90 , o autor entende a pedagogia burocrática como aquela que elabora normas pedagógicas de aplicação burocrática e impessoal (conferir: FORMOSINHO, João; MACHADO, Joaquim. Currículo e organização: as equipes educativas como modelo de organização pedagógica. Currículo sem fronteiras, volume 8 , número 1, pág. 5 -16, jan/jun de 2008).
} 
veiculado tenta aproximação com a prática escolar à medida que se articula com a lógica de sua burocratização (FORMOSINHO, 2007, p. 293-328).

Considera-se, assim, que o gerenciamento da instrução requer uma forma específica de organização devido à especificidade de suas práticas e dos sujeitos políticos que nela transitam. É, pois, impossível entender a movimentação do professor Alberto Voigt sem considerar sua inserção em quadros burocráticos de gerenciamento do ensino. Por outro lado, considerar suas práticas enquanto táticas colabora para o entendimento da burocracia como uma forma específica de gestão das mesmas, através da qual se movimentam sujeitos políticos diversos.

\section{Movimentação funcional e funcionarização da docência}

Vale retomar os passos do professor Voigt de acordo com os jornais já elencados no corpo deste artigo. O mesmo teve sua atuação circunscrita a escolas localizadas no interior do estado de Santa Catarina no momento em que este era governado por Hercílio Luz. Quando da promulgação de legislação estadual e municipal a respeito da nacionalização da instrução, o professor Voigt teve a escola na qual lecionava fechada. Solicitou, pois, sua reabertura. A condição para tanto foi a sua submissão a exames chefiados pelo então Inspetor Federal das Escolas Subvencionadas pela União, Orestes Guimarães - nos quais foi unanimemente reprovado. Ainda descontente, recorreu ao deputado Luiz Abry, que o tranquilizou a respeito da reabertura da instituição. Esse deputado, porém, teve sua atuação política circunscrita por um quadro burocrático que se articulou em torno do gerenciamento da instrução. Ou seja: o ele pouco pôde intervir para a reabertura da escola, já que teve suas deliberações abafadas pelos despachos do Diretor do Ensino, Secretário do Interior e do Governador do Estado.

Apesar da sua irrisória atuação nesse caso específico, a carreira política do deputado Luiz Abry é considerável. Nascido na Alemanha, migrou para o Brasil em 1873, estabelecendo-se no município de Itajaí. Posteriormente, desenvolveu atividades comerciais nos municípios de Blumenau e Pomerode. O início de suas atividades políticas data de 1892, ano em que conseguiu a cidadania brasileira. Ainda em Blumenau, foi presidente do Conselho Municipal entre 1893 e 1895. Já articulado ao Partido Republicano 
Catarinense, elegeu-se oito vezes Deputado Estadual para o Congresso Representativo de Santa Catarina. Participou também de diversas legislaturas nas qualidades de deputado e deputado constituinte (MEMÓRIA POLÍTICA DE SANTA CATARINA, 2018). Quando da ocorrência das rusgas entre Alberto Voigt e a Diretoria da Instrução Catarinense, Luiz Abry ocupava a $11^{\circ}$ legislatura estadual. Também nesse período, seu nome era constantemente referenciado nas atas de reuniões do Congresso Estadual, comumente reportadas no jornal O Dia.

A tática, portanto, avultada pelo professor Alberto Voigt possivelmente veio respaldada na longeva atuação política de um imigrante teuto e pela impressão de que esse pudesse interceder pela reabertura da unidade escolar na qual lecionava. Porém, apesar de tranquilizá-lo quanto aos efeitos de seu pedido, Luiz Abry não pôde intervir na situação.

O gerenciamento burocrático da instrução dependeu da articulação de quadros específicos. Deles fizeram parte a inspetoria estadual e o corpo de inspetores subvencionados pelo governo federal do qual, naquele momento, Orestes Guimarães fazia parte. Integraram tais quadros também os dirigentes de seus órgãos de gestão então a Diretoria Geral da Instrução Pública - e a Secretaria Geral dos Negócios do Estado, a quem ela então se subordinava. A irrisória intervenção do deputado Abry diz, portanto, deve-se à sua não inserção nesses quadros específicos.

A composição dos quadros mobilizados no gerenciamento burocrático da instrução foi possível através de uma dinâmica crescente de funcionarização da profissão docente e da carreira na burocracia do ensino. A concepção do professor como um funcionário articulado a centros específicos de gestão tem também a consequência de colocá-lo em contato direto com um centro organizador de suas práticas e de sua trajetória funcional. Em que pesem as considerações de Nóvoa (1997) sobre a funcionarização do professorado português e as de Michel de Certeau (2002) a respeito da categorização das práticas, esse artigo tematiza uma forma específica de sua articulação através do caso pontual do professor Alberto Voigt. Dessa forma, considerase que sua movimentação funcional no interior dos quadros da docência se insere em um momento crucial da organização da carreira professoral em Santa Catarina. É nesse mesmo período que, coadunando com ideais de nacionalização do ensino e com novas 
representações acerca da instituição escolar, são estabelecidos critérios cada vez mais específicos para o recrutamento e ingresso na carreira do magistério. Esses se articulam com a concepção vigente de escola e são regulados por órgãos específicos de gerenciamento burocrático. Alberto Voigt esbarrou então nos critérios de recrutamento avultados e, para contorná-los, necessitaria de uma nova inserção pela via burocrática. Conforme já foi apresentado, ele não obteve sucesso.

À nacionalização do ensino, associa-se uma nacionalização do corpo docente. O estabelecimento de critérios proibitivos a estrangeiros e seus descendentes, bem como a exigência de exames admissionais foram formas de controle do recrutamento de professores. A essa forma de controle e coerção articulam-se quadros específicos de gerenciamento. Ao processo de nacionalização da instrução corresponderam mais que as rotinas de fechamento de escolas e afastamento de professores. Para que as mesmas fossem operadas, foi necessária a designação de um quadro de funcionários burocráticos responsáveis por seu controle e também a articulação de um centro estratégico legítimo para o gerenciamento burocrático da docência.

A burocratização dos quadros de gerenciamento da instrução trouxe, portanto, efeitos para a organização da carreira docente. Para Crozier (1981), uma organização burocrática é também produto das relações entre os sujeitos que a compõem. Também segundo ele, a vigência do modelo burocrático dependente do controle sobre as fontes de decisão e indecisão. Ao propor sua abordagem funcionalista, considera uma resposta global ao problema da mudança; entendendo o modelo burocrático como portador de disfunções, questiona-se então sobre os limites de sua rigidez ${ }^{13}$. Esse entendimento é aqui tomado como forma para entender a montagem dos quadros de gerenciamento da instrução catarinense, dando destaque à forma de organização de pessoal. Considera, portanto, os efeitos organizacionais e relacionais da organização burocrática da instrução.

Para rastrear as táticas do professor Alberto Voigt, foi necessário conceber sua movimentação funcional no interior desses quadros burocráticos de gerenciamento. Foi também preciso entender sua atuação como cerceada, como parte de uma tática

\footnotetext{
13 O autor utiliza para análise o caso da administração pública francesa, que entende como resistente a mudanças sociais e pressões externas.
} 
cotidiana para permanência na profissão frente a um centro estratégico cada vez mais organizado. São também esses rastros que mostram efeitos pouco avultados da organização burocrática do ensino, que são a reorganização da carreira docente e a defesa e concepção de funções determinadas para a escola. É também Formosinho (2007) quem entende a burocracia como parte de um campo de decisões políticas dentro do qual suas concepções de eficiência e impessoalidade são construídas.

Ou seja: o armamento burocrático de quadros específicos de profissionais não é apolítico. Ele toma como prerrogativas uma representação de escola primária e, por conseguinte, do docente dela responsável. Assim sendo, é também articulado por sujeitos políticos específicos, ocupantes de um local estratégico de mando. A funcionarização da docência e a sua articulação a quadros burocráticos é pensada por pessoas ocupantes de um lugar próprio, de um polo estratégico. A essas manobras os docentes apenas podem responder através da operacionalização de práticas cotidianas, práticas de sobrevivência ligadas à permanência na profissão.

\section{Considerações finais - a nacionalização do professorado catarinense}

As táticas, entendidas como operações cotidianas ligadas à defesa da vida, invariavelmente deixam rastros. Elas o fazem devido a seu caráter polemológico e à sua ligação direta com a existência de sujeitos políticos específicos. São esses rastros que permitem ao historiador o seu mapeamento, compondo assim quadros de análise que permitem a aproximação com as operações avultadas em determinada época. No caso aqui reportado, referente às manobras do professor primário Alberto Voigt, seu rastreamento permitiu circunscrever as tratativas que envolveram a tentativa de reabertura de sua escola e as dinâmicas do processo de nacionalização da docência em Santa Catarina.

A nacionalização da instrução engatilhou dispositivos burocráticos que cercearam a atuação de professores considerados aquém dos critérios de recrutamento avultados. Esses mesmos dispositivos funcionaram como estratégia de coerção, coadunando com a representação de escola nacionalizadora vigente na época. Ou seja: para além da promulgação de legislações específicas, importou a montagem de quadros de 
gerenciamento burocráticos do magistério. Foram esses quadros que forneceram importantes mecanismos de coerção a docentes e discentes, culminado também em dispositivos de fiscalização do ensino e fechamento de escolas.

Não foi por acaso que Alberto Voigt não teve sucesso na reabertura de sua escola. A descendência teuta e o pouco domínio do idioma local em nada contribuíram para que suas deliberações fossem atendidas. Para além disso, a reprovação nos exames aplicados e chefiados pelo então Inspetor Federal das Escolas Subvencionadas pela União, Orestes Guimarães, encerrou suas chances de sucesso. Seu caso é ilustrativo de rotinas administrativas comuns sobre a fiscalização da instrução e do corpo docente. Foi recorrente o anúncio, conforme série de ofícios analisada, de afastamento de docentes e fechamento de escolas. O que torna as operações do professor Voigt centrais é a possibilidade de seu rastreamento, fazendo perceber suas táticas, ainda que pouco exitosas.

É também curioso assinalar sua tentativa de articulação junto a um deputado estadual de mesma descendência que a sua. Mais curioso ainda é destacar que Luiz Abry, um veterano na política partidária catarinense, não obteve sucesso em sua intervenção. Entende-se então que à montagem dos quadros de gerenciamento do magistério correspondeu a formação de um local estratégico próprio para organização das práticas. A esse lugar não correspondia a atuação e influência do deputado, e sim as deliberações legais sobre a nacionalização do ensino e o resultado dos exames apregoados por Orestes Guimarães.

Por fim, o controle da movimentação funcional é possível com a docência funcionarizada e com um polo estratégico de gerenciamento bem estabelecido. Sem esses alicerces, recursos coercitivos perdem a eficácia e o alcance. À nacionalização do ensino, portanto, correspondeu uma nacionalização do professorado. Ela se deu através do recrudescimento nos métodos de recrutamento e permanência na profissão e pelo maior aparelhamento da fiscalização da instrução. Logo, dependeu da organização da Diretoria Geral da Instrução Pública e da articulação dos sujeitos políticos que dela se ocuparam. Em meio a tantas intercepções, as manobras de Alberto Voigt pouco tiveram voz. 


\section{Referências}

CAMPOS, Cynthia Machado. Santa Catarina, 1930: da degenerescência à regeneração. Florianópolis: Editora da UFSC, 2008.

CAMPOS, Cynthia Machado. A política da língua na era Vargas: proibição do falar alemão e resistências no Sul do Brasil. Campinas: Editora da Unicamp, 2006.

CARVALHO, Marta Maria Chagas de. Reformas da instrução pública. In: LOPES, de Eliane Marta Teixeira; FARIA FILHO, Luciano Mendes de; VEIGA, Cynthia Greive. 500 anos de educação no Brasil. 3. ed. Belo Horizonte: Autêntica, 2003a. p. 225-251. (Coleção historial, v 6).

CARVALHO, Marta Maria Chagas de. A República, a escola e os perigos do alfabeto. In: A ESCOLA E A REPÚBLICA E OUTROS ENSAIOS. Bragança Paulista (SP): EDUSF, 2003b. p. 143-164.

CERTEAU, Michel de. Fazer com: usos e táticas. In: A INVENÇÃO DO COTIDIANO: artes de fazer. 15. ed. Petrópolis: Vozes, 2009. v.1. p.91-108.

CERTEAU, Michel de. A operação historiográfica. In: A ESCRITA DA HISTÓRIA. Rio de Janeiro: Forense Universitária, 2002. p. 65-110.

CERTEAU, Michel de. Teoria e método no estudo das práticas cotidianas. In: SZMRECSANYI, Maria Ivone (org.). Cotidiano, cultura popular e planejamento urbano (Anais do Encontro). São Paulo: FAU: USP, 1985. p. 3-19.

CROZIER, Michel. O fenômeno burocrático: ensaio sobre as tendências burocráticas dos sistemas de organização modernas e suas relações na França, com o sistema social e cultural. Brasília, DF: UnB, 1981.

O DECRETO 1290. A República - órgão do partido republicano catarinense, Florianópolis, Ano XV, n. 325, p. 2, 4 nov. 1919.

DIRETORIA GERAL DA INSTRUÇÃO PÚBLICA (SC). Ofício expedido por Henrique Fontes ao Secretário do Interior e Justiça em 20 de fevereiro de 1920. In: ARQUIVO PÚBLICO DO ESTADO DE SANTA CATARINA. Ofícios expedidos pela Diretoria da Instrução Pública 1920/1921. Florianópolis: APESC, [1920]. Ofício 392, folha 20.

FIORI, Neide Almeida. Aspectos da evolução do ensino público: ensino público e política de assimilação cultural no Estado de Santa Catarina nos períodos imperial e republicano. Florianópolis, SC: Secretaria da Educação, 1975.

FORMOSINHO, João; ARAÚJO, Joaquim Machado de. Anônimo do século XX - a construção da pedagogia burocrática. In: OLIVEIRA-FORMOSINHO, Júlia (org.).

Pedagogia(s) da infância: dialogando com o passado, construindo o futuro. Porto Alegre: Artmed, 2007. p. 293-328. 
MEMÓRIA POLÍTICA DE SANTA CATARINA. Biografia Luís Abry. 2018. Disponível em:

http://memoriapolitica.alesc.sc.gov.br/biografia/619-Luis_Abry. Acesso em: 11 jan. 2019.

MOREIRA, João Roberto. A Educação em Santa Catarina. Rio de Janeiro: MEC/ INEP, 1954.

A NACIONALIZAÇÃO do ensino - atitude revoltante do Deputado Luiz Abry. O Estado, Florianópolis, Ano V, n. 1493, p.8, 24 abr. 1920.

O NOSSO aniversário. O Município de Joinville, Joinville Ano I, n. 77, p. 1, 17 maio 1920. p. 1.

NÓVOA, Antonio. Formação de professores e profissão docente. In: Os professores e sua formação. Lisboa: Dom Quixote, 1997. p.13-33.

PIAZZA, Walter. Dicionário político catarinense. [Florianópolis]: Assembleia Legislativa do Estado de Santa Catarina, 1985.

PROCHNOW, Denise de Paulo Matias. As lições da série Fontes no contexto da reforma Orestes Guimarães em Santa Catarina (1911-1935). Orientadora: Gladys Mary Ghizoni Teive. 2009 (Dissertação Mestrado em Educação) - Programa de Pós-Graduação em Educação, Universidade do Estado de Santa Catarina, 2009.

SANTA CATARINA. Disposições relativas ao ensino privado. Florianópolis: Livraria Moderna, 1919.

SANTA CATARINA. Mensagem apresentada à Assembleia Legislativa de Santa Catarina pelo Engenheiro Civil Hercílio Pedro da Luz, vice governador no exercício do cargo de governador do Estado de Santa Catarina. Florianópolis: Imprensa Oficial, 1920. p. 5.

SEM commentarios. O Município de Joinville, Joinville, Ano I, n. 52, p.2, 22 nov. 1919. 